\title{
Overview on Italian hemp production chain, related productive and commercial activities and legislative framework
}

\author{
Luca Giupponi, ${ }^{1}$ Valeria Leoni, ${ }^{2}$ Matteo Carrer, ${ }^{1,2}$ Giulia Ceciliani, ${ }^{1}$ Stefano Sala, ${ }^{1}$ \\ Sara Panseri, ${ }^{3}$ Radmila Pavlovic, ${ }^{1,3}$ Annamaria Giorgi ${ }^{1,4}$ \\ ${ }^{1}$ Centre of Applied Studies for the Sustainable Management and Protection of Mountain Areas - CRC \\ Ge.S.Di.Mont., University of Milan, Edolo (BS); ${ }^{2}$ Department of Law, University of Bergamo, Bergamo, \\ Italy; ${ }^{3}$ Department of Health, Animal Science and Food Safety, University of Milan, Milan, Italy; \\ ${ }^{4}$ Department of Agricultural and Environmental Sciences - Production, Landscape and Agroenergy - \\ DISAA, University of Milan, Milan, Italy
}

\begin{abstract}
Once a very important crop, the cultivation of hemp has seen a significant reduction in Europe for a long time, but it is now subject to direct payments and promotion initiatives. Italy used to be an important producer and exporter of hemp textiles until the Second World War but currently information is lacking regarding the hemp production chain and legislation on the issue is often misunderstood by producers. Moreover, there has been an important development of economic activities connected with hemp, such as the so-called hemp shops or grow shops and the market of a product called cannabis light, the dried inflorescences of industrial hemp.

The aim of the study was to investigate 30 Italian hemp farms in order to identify the characteristics of the production chain and the uses of the crop. Some considerations on this sector in the Italian economic and legislative contest are made and an anonymous web survey on the commercial activities associated with hemp (grow shops) was conducted.

Most farms are multifunctional, $83 \%$ have been set up recent-
\end{abstract}

Correspondence: Giulia Ceciliani, Centre of Applied Studies for the Sustainable Management and Protection of Mountain Areas - CRC Ge.S.Di.Mont., University of Milan, via Morino 8, 25048 Edolo (BS), Italy. E-mail: giulia.ceciliani@unimi.it

Key words: Hemp; Italy; multifunctional farms; Cannabis sativa; legislation; sustainable development.

Acknowledgements: This research was supported by the FISR-MIUR Italian Mountain Lab project. We want to thank Leonardo Zucchelli for the efficient support in the interviews.

Received for publication: 1 October 2019.

Revision received: 2 April 2020.

Accepted for publication: 12 May 2020.

Copyright: the Author(s), 2020

Licensee PAGEPress, Italy

Italian Journal of Agronomy 2020; 15:1552

doi:10.4081/ija.2020.1552

This article is distributed under the terms of the Creative Commons Attribution Noncommercial License (by-nc 4.0) which permits any noncommercial use, distribution, and reproduction in any medium, provided the original author(s) and source are credited. ly (in the last ten years) and directly as hemp producers. They are run by young entrepreneurs ( $57 \%$ holders under 35$)$ and allow the use of marginal abandoned territories ( $43 \%$ of the farms). The 30 farms cultivate 460 ha of hemp and the extension of the field crops is very variable, from small patches in the mountains of 0.001 ha to more than 100 ha farms in the plains (in particular in Campania region). Almost all the farms use the crop to produce more than one end-product (seeds, flour, decorticated seeds, hemp-beer, seeds for animal nutrition and food oil from seeds, seeds and inflorescences harvested for cosmetic use, herbal use and extraction of active ingredients). In some cases, technical use linked to selling of the dry top inflorescences of industrial hemp for smoking was declared and it was found that there has been a significant increase in grow shops in Italy, from 4 in 2002 to more than 700 in 2018.

As emerges from the analyses of European and Italian legislation, there is a need for clear regulations and a system of control by regulatory organisations considering the actual criticalities. At the same time, the renewed appeal of this crop derives from the multiple possibilities of use of the plant and from growing consumer demand for eco-compatible and sustainable products.

\section{Introduction}

Hemp is the common name of the industrial varieties of Cannabis sativa L. (cannabis, Cannabis sativa L., family: Cannabaceae). The uniform taxonomy of $C$. sativa $\mathrm{L}$. has been proven rather challenging and often confusing, due to the huge variability within the same genus (McPartland, 2018). For forensic and legislative purposes, the most important classification of cannabis types is that into the drug-type (marijuana or indica) and the fibre-type (hemp). The main difference between these two is found in the content of the psychotropic component delta-9tetrahydrocannabinol (THC): a high content of THC classifies as drug-type cannabis, while a low content is found in fibre-type cannabis (max. $0.2-0.3 \%$ THC on basis of dry matter in the upper reproductive part of plants), which may also be cultivated for its seeds for human or animal consumption (Hazekamp and Fischedick, 2012). Another important cannabinoid that is, on the contrary, psychotropically inactive is cannabidiol (CBD), that is not regulated by law, $\mathrm{CBD}$ levels tending to be higher in $C$. sativa cultivated for seed or fibre (Rustichelli et al., 1998; Calvi et al., 2018) than in drug-type chemovar. Anyway, chemotypes are highly dependent on the genetics and then the variety (for example there is the Hungarian hemp variety Kompolti known to be rich in CBD), and in addition the plants are exposed to many natural fac- 
tors, which can be very variable among seeds within a single variety (Giupponi et al., 2020). There has been an increasing interest in CBD for herbal and medicinal use worldwide (Amar, 2006).

Cannabis sativa L. is a bast or long-fiber plant, like flax, kenaf, and jute, ranging in height from 1 to 6 meters. It is naturally dioecious, wind pollinated, and the male plants die after producing millions of pollen grains. A small percentage of monoecious plant can naturally occur, and monoecious varieties have been selected in modern times to reduce the agronomic problems related to the sexual vegetative dimorphism present in dioecious varieties, in particular the lack of an efficient mechanisation for harvesting the seeds, and the lower fibre quality and yield losses encountered when harvesting dioecious varieties at seed maturity (Faux et al., 2013). Common modern monoecious varieties are: Futura 75 or Felina 32, while traditional varieties are dioecious, as Finola or Carmagnola.

Once a very important industrial crop, hemp decline after II World War has been unstoppable and at the end of the 1960s it had almost disappeared from most Western European countries (Amaducci et al., 2015), although even before cultivation was already decreasing due to competition from industrial fabrics and cotton, metallic material for navigation ropes and Manila and Juta for packaging during long sea voyages (Peglione, 1919). In the past in Italy, hemp was cultivated mainly in the Po Valley in particular in Emilia-Romagna region. Other territories were in Campania region in an area still called Terra di Lavoro, where there were very fertile and deep soils (Peglione, 1919). Another important, even if smaller, centre was Carmagnola, in Piemonte region, where there was a particularly famous cultivar (Carmagnola). Italian fibre was the best on the market and the superior quality was not due to the genetics of the plants but to the method of maceration and then processing of the raw fibre in the Italian countryside (Bruck,1911) Production in Italy was exclusively for fibre and textiles, while seeds were produced and used in Asia and drugs and medicinal varieties only in Mexico, India, Turkey and Africa (Peglione, 1919).

Renewed interest in hemp cultivation began in the early 1990s when the farming of hemp was promoted throughout the European Union, but after more than 20 years of promotion hemp was still a niche crop, cultivated on 10,000-15,000 ha in the European Union (Carus et al., 2013). After that, hemp area in the European Union countries reached record levels in 2018, with nearly 40,000 ha (EIHA website https://eiha.org/, visited the $30^{\text {th }}$ of March).

Over the last 30 years, France has been the leading country in Europe for the cultivation of hemp and a relatively stable market for hemp products has favoured the development of new genotypes and cultivation systems (Bouloc, 2013) and can be seen as an important case study: the call for new genotypes and improved crop management that, coupled to a suitable mechanisation and processing system can lead to the production of high yields of fibres of defined quality and seeds, is perfectly in line with the principles of the modern bioeconomy (Amaducci et al., 2015). The Italian farmers association Coldiretti presented an important study at the Global Food Innovation Summit 2018, titled: The new canapa economy, showing that that Italian production of hemp increased from 400 ha cultivated in 2013 to almost 4000 estimated in 2018 and assessing the renewed interest in this cultivation.

Europe promotes the cultivation of hemp through direct payments (Reg (Ce) N. 2860/2000 of the European Commission $27 / \mathrm{Dec} / 2000$ ) and recognises it as an important crop for many innovative uses in the new bio-based economy (as it is assessed in the Summary of the position papers received in response to the European Commission's Public on-line consultation Bio-based economy in Europe: state of play and future potential, opened from February to May 2011). Hemp (C. sativa L.) is a multiuse, multifunctional crop that provides raw material to a large number of traditional and innovative industrial applications (Amaducci et al., 2015). From fibre combing and knitting or weaving, in fact, fabrics can be obtained for textiles as clothing, or furniture and outdoor gear (CELC website, the European Confederation of Flax and Hemp, http://www.mastersoflinen.com, visited the $30^{\text {th }}$ of March). Innovative uses are in eco-building (Elfordy et al., 2008; Jarabo et al., 2012), as reinforcement or insulation in composites materials in automotive (Holbery and Houston, 2006). The seeds are being studied as a superfood for their content in unsaturated fatty acids and protein and the absence of antinutritional components (Malomo et al., 2015). The dust and the shives can be used as animal litter or organic mulch for gardens and crops or again in eco building. Hemp can also be used to produce paper. The inflorescences, finally, can be important resources of interesting secondary metabolites for industry, food, herbal medicine or cosmetics. Some authors have already proposed even a dual crop production, for example seed plus fibre (Tang et al., 2016) or fibre plus essential oil for the cosmetic industry (Bertoli et al., 2010). Some production chains from hemp present technological issues and technological breakthroughs have yet to occur, as what happens for fibre production (Randall et al., 2004; CELC and EIHA personal communications), where the study of some agronomical and technological solutions, as the comparison of varieties together with different processing methods (as bio-degumming or dew-retting) have been started just recently (Musio et al., 2018).

The production chain of cannabis light, instead, is not clear and sufficiently regulated. Recently, it has become common in Italy to find commercial activities connected with hemp, that are usually called Grow Shops. A grow shop or commercial activity related to hemp usually sells material to grow hemp plants (gardening materials such as aeroponics and hydroponics, lighting, mini-greenhouses, seeds, soils and substrates, fertilisers and pesticides, etc.,) and also products of hemp, both food and dietary supplements, cosmetics, clothing and green building items at times, all obviously linked to hemp, but the main product are dried inflorescences for technical use.

Hemp is then a crop with unique characteristics, linked to the existence of very different chemovars and the presence of psychotropic substances, which implies many legal and social aspects in its cultivation, with the necessity of clear rules and a clear legislative framework for farmers and generally for hemp stakeholders. Another exclusive aspect, as it was explained previously, is its multifunctionality and the recent renewed interest in Europe and Italy, this last being also a traditional cultivation area of hemp, as we saw, but with a very long period of neglect with the connected need of training and technological renovation.

Based on the above considerations, the aim of this study was then to conduct a survey on a sample of Italian farms that produce hemp, to understand the characteristics of the production chain and the purposes of crop production. In addition, following methods applied for leisure cannabis (Decorte, 2010), an anonymous web questionnaire on commercial activities associated with hemp (commonly named Grow Shops) was conducted. Finally, some considerations on this sector in the Italian economic and legislative contest were made and the most important European and Italian regulations about the cultivation of hemp in the last few years were summarised. The phenomenon of cannabis cultivation is a very good example of an agronomic topic having impact on social themes and that needs a multidisciplinary approach. 


\section{Materials and methods}

The interviews were performed from March 2018 to March 2019. Firstly, a questionnaire template to administer to farmers (in person, telephonically or by email) was created. The farms available for the interview were found through contacts from Coldiretti association and Confagricoltura association, the two main Italian Agricultural Associations, Assocanapa and Federcanapa (the two mail Italian Hemp Associations) and hemp events. Other than that, the questionnaires were sent through the contact database of the research centre Ge.S.Di.Mont of about 20,000 contacts. The questionnaires collected the following information: farm name and address, if the farm was set up for producing hemp or was converted from other productions, if the farm belongs to young entrepreneurs, if it is in marginal territories in the mountains, the cultivated hemp surface, the variety, the provenience of the seeds, what the crop harvest is used for, if there are multifunctional or educational activities associated, and all that regards agronomic practices: use of pesticides or irrigation, soil preparation and fertilisation, mechanisation. Finally, there was an open question asking for opinions on the strengths and weaknesses of the hemp production chain.

The survey on Grow Shops was performed following methods applied for leisure cannabis (Decorte, 2010): an anonymous web survey on the commercial activities associated with hemp was conducted. All Italian regions were considered, looking for Grow Shops starting from the main cities and surroundings.

Then, a brief review of the European Legislation through the Commission portal (https://eur-lex.europa.eu/) and of Italian Legislation was conducted.

\section{Results}

\section{Hemp farms overview}

Of the questionnaires realised, 30 were selected as they contained comprehensive data completed in all parts and referred to farms randomly scattered throughout the Italian territory. Data were elaborated regarding these 30 farms (Figure 1). The results of this survey are just to intend as an overview built on a limited number of case studies.

Our first question investigated the origin of the activity, if the farm started as a hemp farm or was converted to hemp from other cultivations and finally, for how many years the farm has been cultivating hemp. Results showed that $83 \%$ of the farms were set up directly for the cultivation of hemp, while $17 \%$ were converted from a different crop (mainly horticulture). Almost all the hemp farms (97\%) were set up recently (within the last ten years), because hemp cultivation in Italy was officially permitted only from the 1990 s. $57 \%$ of the holders were found to be under 35 years old and $43 \%$ are totally in a mountain territory. The survey showed that all together the 30 farms cultivate 453.7 ha of hemp open fields and 0.78 ha of hemp in greenhouse, for a total of about 460 ha of hemp cultivation. Four farms (13\%) have both protected and open field crops. The size of hemp field crops is very variable, from small patches in the mountains of $100 \mathrm{~m}^{2}$ to 152 ha (Figure 2). Moreover, our survey described the most common varieties grown by the farms studied. The most popular varieties are Fibranova, Futura 75, Kompolti, Uso 31, Finola and Carmagnola (both traditional and Selected Carmagnola, while also Felina 32 is used on four farms) (Figure 3). A direct connection between the choice of a variety and the final product was not found. As regards the provenience of the certified seeds, they come both from Italy, through hemp associations and cooperatives (Tecnocanapa,
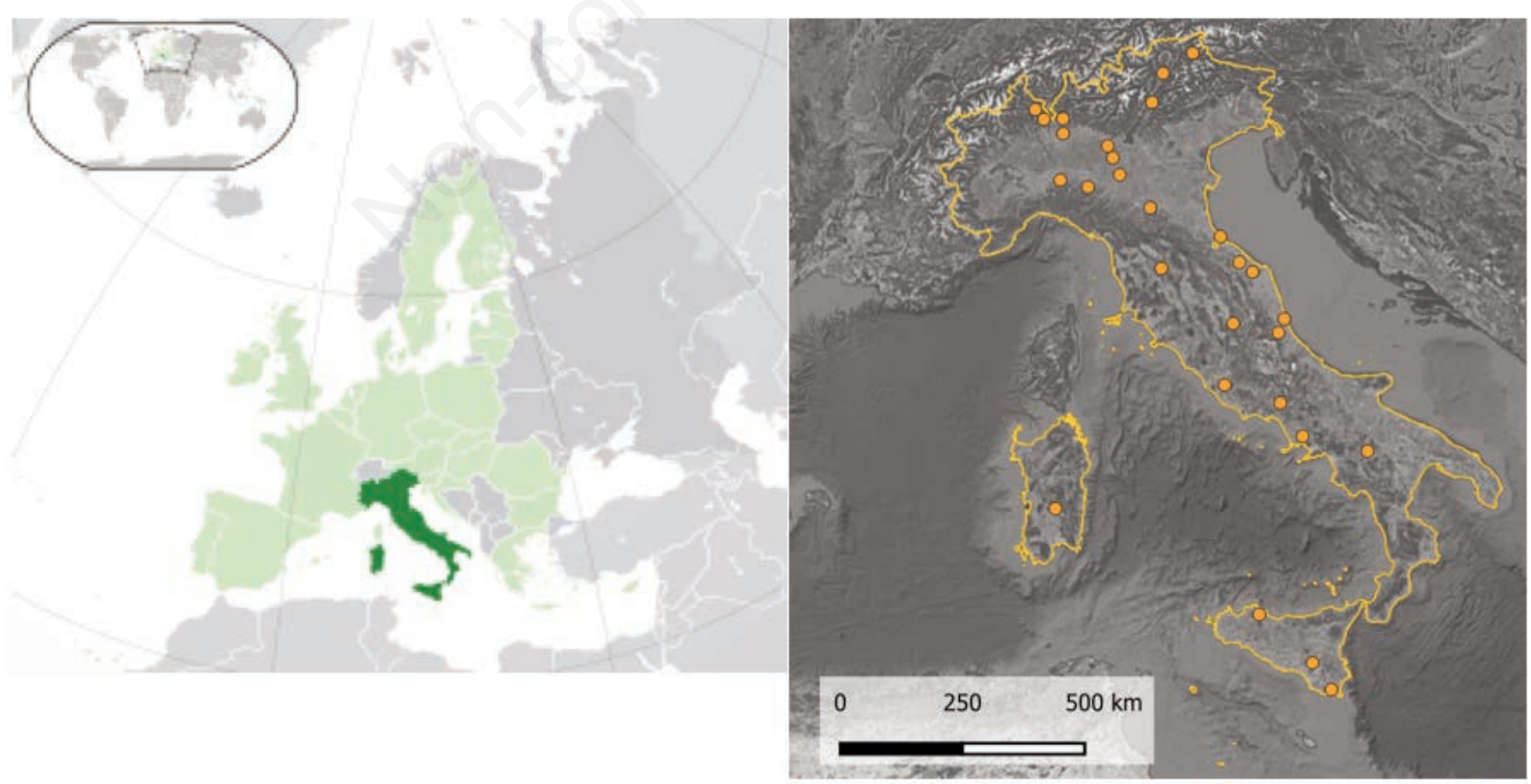

Figure 1. Map of farms (orange dots) interviewed distributed throughout the Italian Territory. 
Assocanapa and Federcanapa) and from Europe, in particular Germany and France, followed by North-East Europe (Figure 4) As regards irrigation, only $30 \%$ of farms declared that they needed irrigation, while $60 \%$ declared they did not; for pesticides, instead, only $7 \%$ of farms declared their use. Moreover, fertilisation follows sustainable and organic principles in almost all farms $(37 \%$ declared that they use organic fertiliser, compost or green manure, $27 \%$ declared not using any fertiliser). Only one farm out of 30 uses chemical fertilisation together with organic manure. One farm uses new techniques of bio-fertilisers (soil activators) and leaf fertilisation. Planting distances vary according to the output of the crop (fibre, seeds or inflorescences) and the size of the field (very small fields are prepared by manual sowing), in agreement with the findings of Amaducci et al. (2015). As regards soil tillage, very different situations were found, also depending on the level of mechanisation and size of the farm. 2 farms (7\%) declared they have no mechanisation at all, one of them being a hemp didactic farm. In just one farm (3\%) there is no-tillage, while instead in $70 \%$ of the farms, soil is prepared by mechanical ploughing followed by harrowing in $27 \%$ cases or harrowing and soil milling (3\%) or ploughing followed directly by soil milling (20\%). Only $13 \%$ of farms prepared the soil only by ploughing. Sowing is done both by seedscattering and precision sowing, sometimes followed by use of a ground roller (7\%). As regards harvesting, seeds are usually collected mechanically by combine harvester $(30 \%$ of farms have a combine harvester) while inflorescences are collected manually and only one farm was found to use professional machinery for flos collection: a trimmer and a resonator. Finally, straw is collected using balers. In particular, only one farm could be considered completely mechanised in all agricultural operations, starting from plough, disc harrow, tine harrow, seeder, ground roller for the ground preparation to combine harvester for seeds, mower, rake and baler for straw. Other than that, $30 \%$ of farms declared that they accompany their activity with cultural, multifunctional and educational activities, as courses and public events, educational laboratories (for the production of food, food oil or cosmetics), environmental conservation and remediation, gastronomy showrooms. Almost all the farms use the crop for the production of more than one end-product (Table 1). In $63 \%$ of cases the cultivation leads to the production of flour for baking as well as decorticated seeds to sell as superfood, while in $23 \%$ cases the farm wants to produce hemp-beer. In $7 \%$ of cases seeds are produced for ani-

Table 1. Use of the harvest in the farms interviewed; in the most of the farms $(73 \%)$ hemp is a multi-end use crop.

\begin{tabular}{lc} 
Output of hemp farm & Number of farms \\
Production of certified seed & 2 \\
Seed to sell to mills & 5 \\
\hline Raw fibre & 4 \\
Technical use & 5 \\
\hline Animal food & 2 \\
Flour or decorticated seeds for food & 19 \\
\hline Production of a typical liquor & 1 \\
Production of aromatic wine & 1 \\
\hline Production of beer & 7 \\
Cosmetic use of inflorescences and seeds & 13 \\
\hline Food oil extracted from seed & 6 \\
Inflorescences for herbal use & 12 \\
\hline Inflorescences to sell for extraction active ingredient & 5 \\
\hline
\end{tabular}

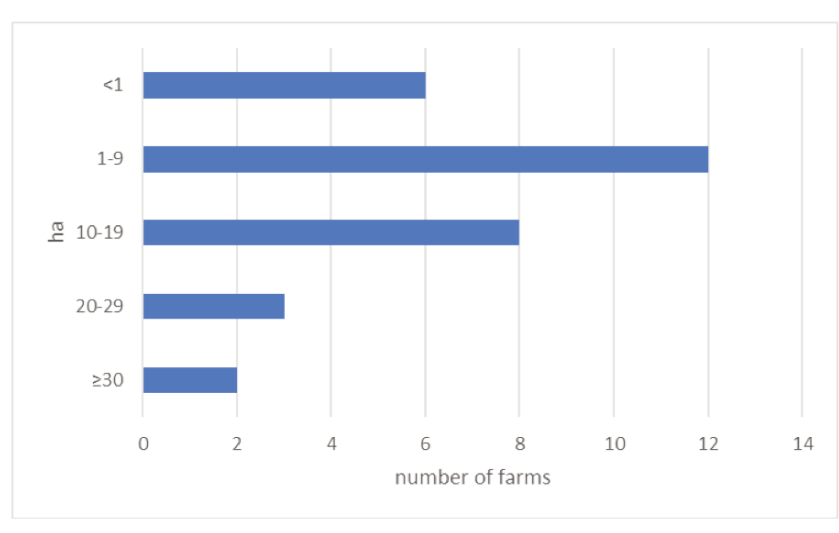

Figure 2. Size of hemp crops in the farms interviewed.

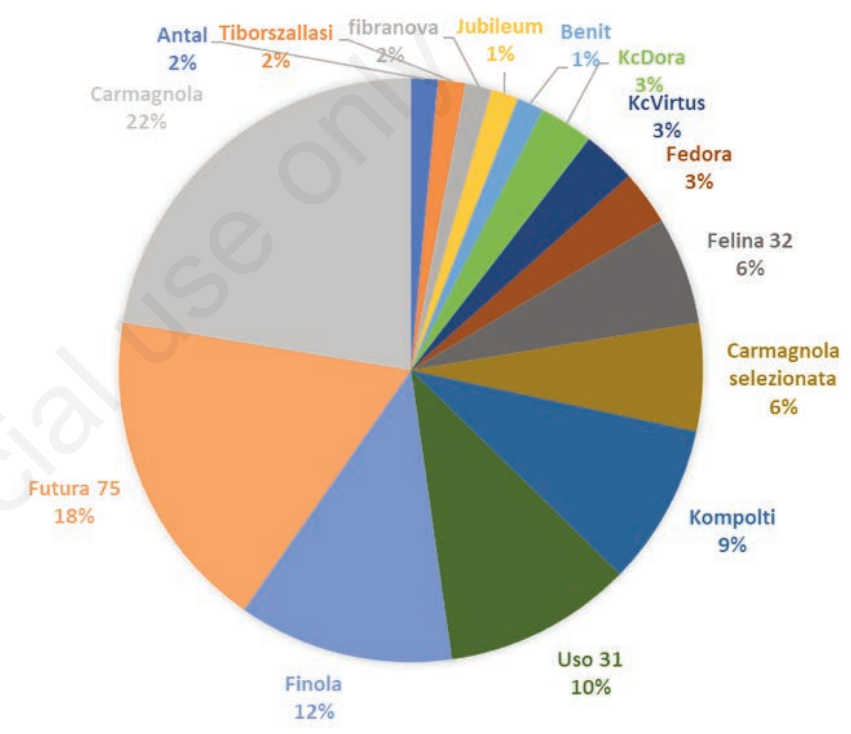

Figure 3. Varieties most cultivated in the interviewed farms; most of the farms cultivated more than one variety.

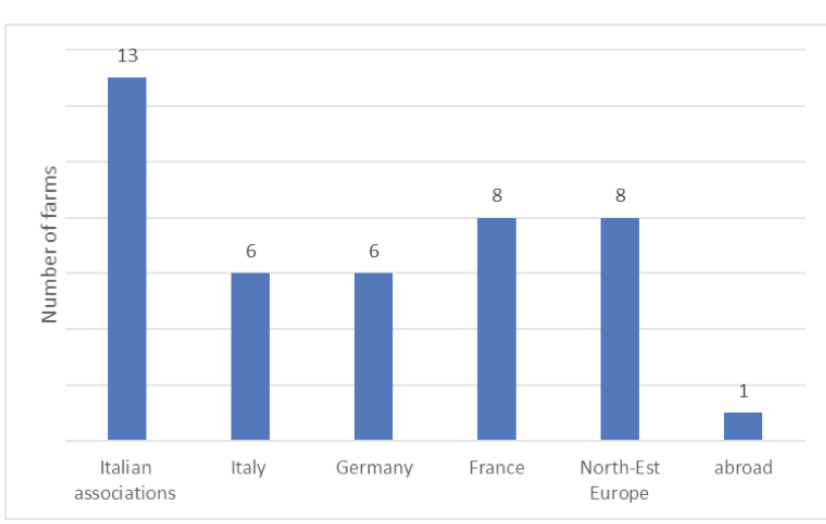

Figure 4. Source of certified seeds in the farms interviewed; most of the farms cultivated more than one variety; an important source are Italian associations (Assocanapa, Federcanapa and Tecnocanapa). 
mal nutrition and in $20 \%$ for food oil from seeds. Finally, there is some direct selling to mills of the seeds without transformation on the farm. In $43 \%$ of cases seeds and inflorescences are harvested for cosmetic use, while in $40 \%$ of cases inflorescences are produced for herbal use and extraction of active ingredients. One of the farms declared technical use as the only output of the crop and another 4 farms (13\%) produced some inflorescences, other than the principal product, for this purpose.

In this research, farmers were also invited to give an opinion on the strengths and the weaknesses of the hemp production chain. The results are shown in Table 2. Positive opinions were mostly linked to the good quality of the crop for its role in agricultural alternations, the fact that it can be grown organically and its multiple end-use and originality. Negative opinions were mostly linked to the need for research on mechanisation and for the textile production chain, the lack of a national production chain and expertise to assist farmers and finally the need for a clear legislation and a more efficient bureaucracy for the productive system.

\section{Commercial activities}

In our survey, 776 hemp shops were counted, mainly in Lombardy, Lazio and Campania (Figure 5) and mostly set up in the last three years (Figure 6). Many of them even opened franchising activities and more than one shop in the same city. The increase in the number of grow shops was very significant, starting from few in early 2000 to more than 700 in March 2019.

This data testifies that selling top inflorescences of industrial hemp of different cultivars and the exponential growth of grow shops in Italy are phenomena worth considering and analysing.

\section{European and Italian Regulations}

The Commission Regulation (EC) No1251/1999 and the following 2860/2000, to include flax and hemp grown for fibre in the support system for producers of certain arable crops were a very important step for hemp cultivation in Europe. Article 5a of Regulation (EC) No 1251/1999 lays down, on the one hand, that the tetrahydrocannabinol content of varieties used must not exceed $0.2 \%$ and, on the other hand, that the Member States must establish a system for verifying the tetrahydrocannabinol content of hemp crops, provided a Common Catalogue of Varieties of Agricultural Plant Species as fibre plants allowed and finally, it was established that the labels contained on packaging or any other equivalent document should be transmitted to the competent authorities of the Member State to ensure the use of certified seeds.

The commission also established a common practice for laboratories to quantify $\Delta$ 9-THC (tetrahydrocannabinol) in hemp in annex XIII of the Commission Regulation (EC) No1251/1999 (Table 3), and also established that member states must check at least $30 \%$ of the areas of hemp grown for fibre for which area payment applications have been made, and at least $20 \%$ of areas if a Member State introduces a system of prior approval for such cultivation. Further, Member States must send a report on the THC content findings to the Commission by 15 November at the latest of the marketing year in question. The report shall indicate, for each variety, how many samples collected exceed the THC content of $0,1 \%$, for which further controls are expected for the following marketing year.

The further Commission Regulation (EC) No 796/2004 of 21 April 2004 laying down detailed rules for the implementation of cross-compliance, modulation and the integrated administration and control system provided for in Council Regulation (EC) No 1782/2003 establishing common rules for direct support schemes under the common agricultural policy and establishing certain support schemes for farmers insists on the need for controls by the member states.

Finally, the Commission Delegated Regulation (EU) 2017/1155 of 15 February 2017 points out some specifications on the use of hemp as a catch crop instead of main crop. For the European commission, hemp can be considered a catch crop only if sown after 30th June of a given year. In this case, crops of hemp must continue to be cultivated under normal growing conditions in accordance with local practice for at least 10 days from the date of the end of flowering so that the necessary checks can be made.

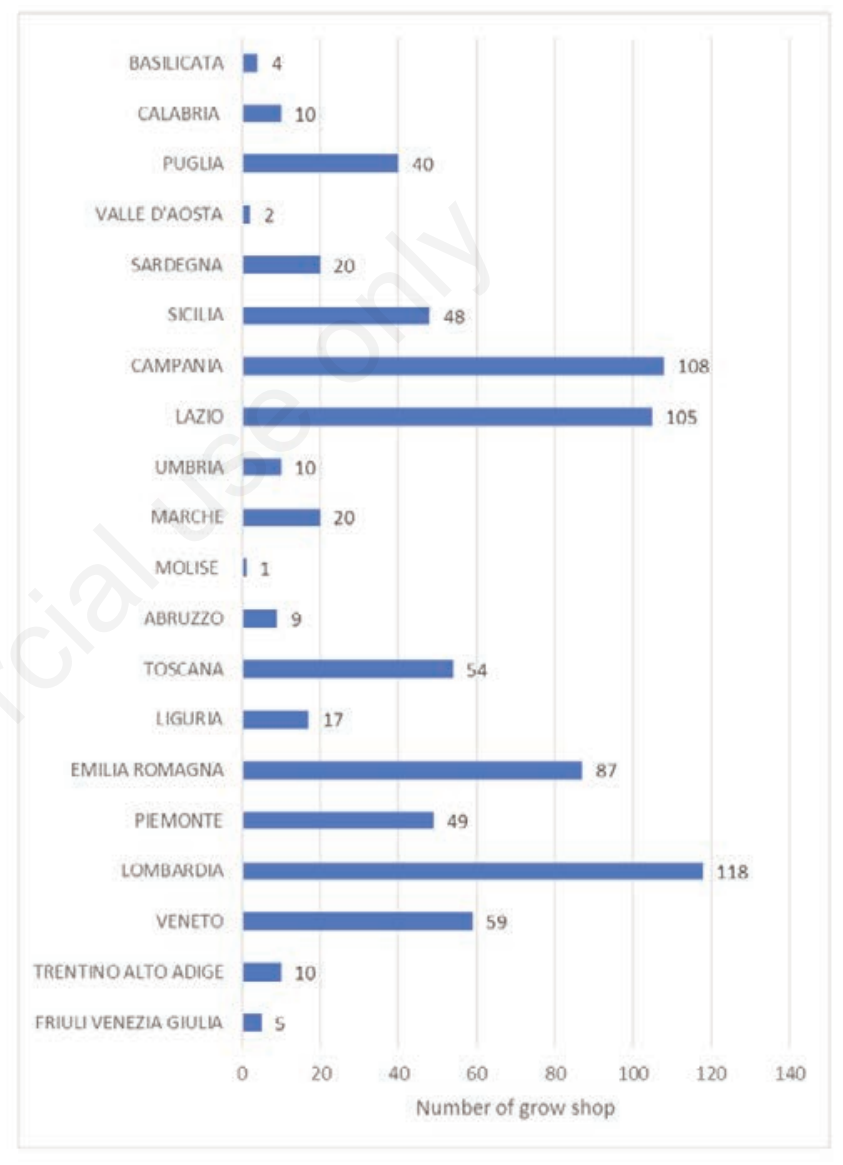

Figure 5. Grow shops in Italy in 2019 for each Italian Region.

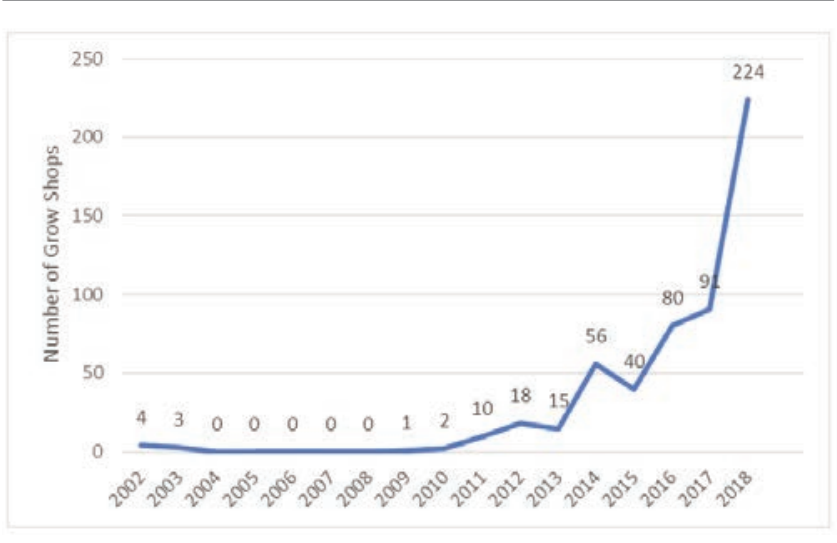

Figure 6. Number of grow shops set up from 2002 to 2019. 
The two main European Hemp Associations are CELC, the European Confederation of Flax and Hemp, and EIHA, the European Industrial Hemp Association.

Focusing the attention on Italy, the first fundamental law about hemp is Law 685/1975 (Disciplina degli stupefacenti e sostanze psicotrope. Prevenzione, cura e riabilitazione dei relativi stati di tossicodipendenza), following the Convention on Narcotic Drugs (adopted in New York on 30 March 1961, amended in Geneva on 25 March 1972, whose ratification and execution in Italy had taken place just the year before with the law of 5 June 1974, n. 412). in the Lex of $22^{\text {nd }}$ December 1975 , n. 685 , in fact, art. 1 contained the following definitions: $b$ ) the term 'cannabis' refers to the flowering or fruiting tops of the cannabis plant (excluding the seeds and leaves that are not joined to the apexes) whose resin has not been extracted, whatever their application; c) the term 'cannabis plant' means any plant of the cannabis type; $d$ ) the term 'cannabis resin' means the separate, raw or refined resin obtained from the cannabis plant [...]. Italian legislation in this case calls the cannabis plant for drug production Indiana but the taxonomy of this plant is very controversial (Mc Partland, 2018). In this way, the new Italian law banned hemp cultivation for the first time, referring to hemp used for the manufacture of drugs. This did not provoke big changes to agriculture, as, from historical analysis, industrial hemp had almost disappeared, while it is common knowledge that marijuana was subject to mass consumption due to the youth movements of the 1960s. Also, in USA in 1937 the Marijuana Tax Act totally prohibited the cultivation of Cannabis sativa L., without distinguishing between hemp and marijuana.

However, in the next law, n. 162/1990 about Narcotic Drugs, the novelty is the fact that Cannabis indica is specified as $(2 \%$ Delta9 THC). The meaning of this indication has never been specified. It refers to an average THC content in marijuana, once set at $50 \mathrm{mg}$, probably, but it could refer to inflorescences (in accordance with the New York Convention) or to the whole plant (as is common practice in laboratory analysis). The maximum limit of THC (tetrahydrocannabinol), however, is not specified as a general limit of the crop cultivar or maximum in $50 \mathrm{mg}$ of marijuana, so there is still no clear distinction between hemp as an industrial crop and the C. sativa understood as marijuana. In law 49/2006, moreover, there is no difference between hemp and Marijuana, talking about Delta9-tetrahydrocannabinol (THC), the dry indication of the active ingredient THC involves any type of cannabis, so there is still a grey zone of confusion between the drug and the industrial crop.

Following the promotion of hemp cultivation in Europe thanks to above-mentioned direct payment rules, in 1997 the Association of hemp growers Assocanapa lobbied for a circular (Ministry of Agricultural and Forestry Policies - Circular 2 December 1997, n. 73) aiming to protect hemp farmers. Hemp could be cultivated if farmers agreed to accept controls and they were required to communicate their activity to the public security authority. In the circular, the Ministry defines, together with national police bodies, an operational path to carry out the necessary checks; promotes the procurement on the international market of the certified seeds necessary for the initial investment, for experimental and demonstration purposes, of an area of approximately $1000 \mathrm{Ha}$; establishes that the cultivation of industrial hemp, both for paper and textile uses, must take place in limited areas - limited and perfectly identified, communicating this to the public security authority.

Following the EU regulation, a new circular was therefore issued in 2002 relating to Hemp destined for the production of fibres (Cannabis sativa - NC 530210 00), which envisages support rules for farmers and reaffirms the limit of THC not exceeding $0.2 \%$. For the same reason, legislation about Narcotic Drugs was also updated in 2014, with the decree law 20th March 2014 n. 36, which effectively reinstates the 1990 differentiation for drugs, but with some new features compared to the July 12th 1990 decree: the conversion law n. 79/2014 art. 26 of the T.U. n. 309/1990, after the prohibition of the cultivation of the plants, inserts the exception of cultivated hemp exclusively for the production of fibres or for other industrial uses, different from specified in article 27, consented by EU legislation.

Finally, a declaration from MIPAF (Ministery of Agriculture and Forestry) (Circular MIPAF n.1 08.05.2002 - Regime di sostegno a favore dei coltivatori di canapa industriale destinata alla produzione di fibra (Cannabis sativa - NC 53021000 ) confirms the European regulation, that the payment per area is subject to the use of hemp varieties with a THC content not exceeding $0.2 \%$ and to the use of certified seed varieties listed in Annex XII of EC

Table 2. Some opinions of farmers interviewed on strengths and weaknesses of the hemp production chain in Italy. Not all the farmers agreed to answer this question.

\begin{tabular}{ll}
\hline Strengths & \multicolumn{1}{c}{ Wealknesses } \\
\begin{tabular}{ll} 
Originality of the value chain, multiple end-use of the crop & Need for research on mechanisation, lack of a national production chain \\
Very good crop for agricultural alternation practices & Need for more centres of transformation and more expertise for farmers \\
\hline Opportunity for the local market, possibility of cooperation with research centres & Need for research to build textile production chain \\
No need for pesticides and chemical fertilisation & Market and production chain still not yet developed \\
\hline Opportunity for young people to approach agriculture with an original value-chain & Need for clear legislation \\
Value chain crop, superfood & Need for clear legislation and a better knowledge of the variety to sow in a specific territory \\
\hline Very good rotation crop & Need for clear legislation \\
Opportunity for a small family farm & Need for more centres of transformation and more expertise for farmers \\
\hline Very good raw material & Market and production chain still not yet developed, need for research on mechanisation of process \\
Research and new knowledge opportunity & Need for research on mechanisation of process \\
\hline Very good quality in mountain territories & Need for expertise \\
Quality and originality of the products, opportunity for the territory & Need for clear legislation and less bureaucracy \\
& Need for research on mechanisation, lack of a national production chain \\
\hline Quality of a product of an uncontaminated environment, even if low production & Lack of a national production chain and clear legislation
\end{tabular} \\
\hline
\end{tabular}


Table 3. European common practice for laboratories to quantify $\Delta 9$-THC (tetrahydrocannabinol) in hemp.

\section{Community method for the quantitative determination of $\triangle 9$-THC (tetrahydrocannabinol) content in hemp varieties}

\section{Scope and area of application}

This method seeks to determine the $\Delta$ 9-tetrahydrocannabinol (THC) content of varieties of hemp (Cannabis sativa L.).

As appropriate, the method involves applying procedure A or B herein described.

The method is based on the quantitative determination of $\Delta$ 9-THC by gas chromatography (GC) after extraction with a suitable solvent.

1.1. Procedure A

Procedure A is used for checks on production as provided for in Article 5a(2) of Regulation (EC) No 1251/1999.

1.2. Procedure $B$

Procedure $B$ is used in cases as referred to in the third subparagraph of Article $7 \mathrm{~b}(1)$ of this Regulation and for checking that the conditions laid down in the second subparagraph of Article 5a(1) of Regulation (EC) № 1251/1999 are fulfilled with a view to inclusion on the list of varieties of hemp eligible for aid from the 2001/02 marketing year.

\section{Sampling}

2.1. Samples

- Procedure A: in a standing crop of a given variety of hemp, take a $30 \mathrm{~cm}$ part containing at least one female inflorescence of each plant selected. Sampling is to be carried out during the period running from 20 days after the start of flowering to 10 days after the end of flowering, during the day, following a systematic pattern to ensure that the sample is representative of the field but excluding the edges of the crop. Member States may authorise sampling to be carried out during the period from the start of flowering to 20 days after the start of flowering provided that, for each variety grown, other representative samples are taken in accordance with the above rules during the period from 20 days after the start of flowering to 10 days after the end of flowering;

- Procedure B: in a standing crop of a given variety of hemp, take the upper third of each plant selected. Sampling is to be carried out during the 10 days following the end of flowering, during the day, following a systematic pattern to ensure that the sample is representative of the field but excluding the edges of the crop. In the case of dioecious varieties, only female plants must be taken.

2.2. Sample size

- Procedure A: the sample is to comprise parts of 50 plants per field;

- Procedure B: the sample is to comprise parts of 200 plants per field.

Each sample is to be placed in a fabric or paper bag, without crushing it, and sent to the laboratory for analysis.

The Member State may provide for a second sample to be collected for counter-analysis, if required, to be kept either by the producer or by the body responsible for the analysis.

2.3. Drying and storage of the sample

Drying of the samples must begin as soon as possible and, in any case, within $48 \mathrm{~h}$ using any method below $70^{\circ} \mathrm{C}$. Samples should be dried to a constant weight and to a moisture content of between $8 \%$ and $13 \%$.

After drying, store the samples without crushing them at below $25^{\circ} \mathrm{C}$ in a dark place.

\section{Determination of THC content}

3.1. Preparation of the test sample

Remove stems and seeds over $2 \mathrm{~mm}$ in size from the dried samples.

Grind the dried samples to obtain a semi-fine powder (passing through a $1 \mathrm{~mm}$ mesh sieve).

The powder may be stored for 10 weeks at below $25^{\circ} \mathrm{C}$ in a dark, dry place.

28.12.2000 EN Official Journal of the European Communities L 332/75

3.2. Reagents and extraction solution

Reagents

- $\Delta$ 9-tetrahydrocannabinol, pure for chromatographic purposes,

- Squalane, pure for chromatographic purposes, as an internal standard.

Extraction solution

- $35 \mathrm{mg}$ of squalane per $100 \mathrm{~mL}$ hexane.

3.3. Extraction of $\triangle 9$-THC

Weigh $100 \mathrm{mg}$ of the powdered test sample, place in a centrifuge tube and add $5 \mathrm{ml}$ of extraction solution containing the internal standard.

Place in an ultrasound bath and leave for 20 minutes. Centrifuge for five minutes at 3000 r.p.m. and then remove the supernatant THC solution. Inject the solution into the chromatograph and carry out a quantitative analysis.

3.4. Gas chromatography

(a) Apparatus

- gas chromatograph with a flame ionisation detector and a split/splitless injector,

- column allowing good separation of cannabinoids, for example a glass capillary column 25-m long and $0.22 \mathrm{~mm}$ in diameter impregnated with a 5\% non-polar phenylmethyl-siloxane phase.

(b) Calibration ranges

At least three points for procedure $\mathrm{A}$ and five points for procedure $\mathrm{B}$, including points 0.04 and $0.50 \mathrm{mg} / \mathrm{mL} \Delta$ 9-THC in extraction solution.

(c) Experimental conditions

The following conditions are given as an example for the column referred to in (a):

- oven temperature: $260^{\circ} \mathrm{C}$

- injector temperature: $300^{\circ} \mathrm{C}$

- detector temperature: $300^{\circ} \mathrm{C}$.

(d) Volume injected: $1 \mu \mathrm{L}$.

\section{Results}

The findings are to be expressed to two decimal places in grams of $\Delta$ 9-THC per 100 grams of analytical sample dried to constant weight. A tolerance of $0.03 \mathrm{~g}$ per $100 \mathrm{~g}$ applies.

- Procedure A: one determination per test sample.

However, where the result obtained is above the limit laid down in the second subparagraph of Article 5a(1) of Regulation (EEC) No 1251/1999, a second determination must be carried out per analysis sample and the mean value of the two determinations will be taken as the result.

- Procedure B: the result corresponds to the mean value of two determinations per test sample. 
Regulation 1251/1999 and later mod. The declaration also states the method to be used by the competent authorities of the Member State to detect the amount of THC on a percentage of the areas planted with hemp grown for fibre. It finally states that farmers must notify the planting of Cannabis sativa to the nearest police station (State Police, Carabinieri Corps, Guardia di Finanza, etc.).

This declaration precedes the fundamental legislation of 2 December 2016, n. 242, that clearly allows the cultivation of hemp, even without notification of the crop to control bodies.

The legislation is also a document of promotion and support of this cultivation as it says: The present law contains rules for the support and promotion of the cultivation and supply chain of hemp (Cannabis sativa L.), as a crop capable of contributing to the reduction of the environmental impact in agriculture, to the reduction of the consumption of soils and desertification and loss of biodiversity, as well as a crop to be used as a possible substitute for surplus crops and as a rotation crop. It confirms that the varieties admitted are the ones indicated by the European Commission catalogue, and that these varieties are excluded from the legislation on drugs dated 162/1990. It is also coherent with the Commission regulations on the use of certified seeds and production, to ensure the use of certified seeds, of the labels contained on packaging or any other equivalent document. The State Forestry Corps are responsible for controls, as indicated by European regulations, although other bodies can carry out inspections if considered necessary. With up to $0.6 \%$ of $\mathrm{THC}$ in crops, no penal responsibility is attributed to the farmer and the control bodies can decide on destruction of the crops if THC is over $0.6 \%$.

Also, the legislation promotes the development of sustainable territorial value chains based on industrial hemp cultivation with the production of food, cosmetics, biodegradable raw materials and innovative semi-finished products for industries in different sectors and the realisation of bioengineering works, land reclamation, educational and research activities.

Final products which can be obtained from the crop are also clearly stated: i) foods and cosmetics produced exclusively in compliance with the disciplines of the respective sectors; ii) semi-finished products, such as fibre, shives, powders, wood chips, oils or fuels, for supplies to industries and craft activities in various sectors, including energy; iii) material destined for the practice of green manure; iv) organic material for bioengineering works or products useful for green building; v) material aimed at phytodepuration for the remediation of polluted sites; vi) crops dedicated to educational and demonstration activities as well as research by public or private institutions; vii) crops for nursery gardening

The legislation also promotes research and development and allows public research institutes to reproduce for a year the certified seeds purchased in the previous year, using it to produce small amounts of a demonstrative, experimental or cultural nature, subject to communication to the Ministry of Agricultural, Food and Forestry Policies. Educational activities, in fact, are also encouraged, such as training in favour of those who operate in the hemp supply chain and disseminate, through specific information channels, the knowledge of the properties of hemp and its uses in the agronomic, agro-industrial, nutraceutical, bio-building, biocomponent and packaging fields.

Finally, the legislation says: the implementation of the provisions of this law shall be carried out within the framework of the human, instrumental and financial resources available under current legislation and, in any case, without new or greater costs for public finance. The present law, bearing the seal of the State, will be included in the official Collection of normative acts of the
Italian Republic. Anyone responsible for observing it and enforcing it as a state law is obliged to do so.

Then, the Circular dated 22 May 2018: Clarifications on the application of the law of 2 December 2016, n. 242 specifies that production must start only from seeds, not in an agamic way. Specifically regarding the inflorescences of hemp, the circular specifies that these, although not expressly mentioned by law $n$. 242 of 2016, neither between the purposes of the crop nor its possible uses, fall under article 2, paragraph 2, letter g), entitled, 'Lawfulness of the cultivation', or rather in the field of the cultivations destined to nursery gardening, provided that such products derive from one of the accepted varieties, included in the common catalogue of varieties of agricultural plant species, whose total THC content of the cultivation does not exceed the levels established by the legislation, and provided that the product does not contain substances declared harmful to health by the Competent institutions. For the purposes of the correct application of law no. 242 of 2016 and the development of the cultivation of hemp in Italy, the maximum circulation of this circular is recommended. It allows the sale of inflorescences but prevents cuttings.

However, some of the cannabis varieties allowed by the European Union, which must contain less than $0.2 \%$ THC, contain a significant percentage of $\mathrm{CBD}$, which is not a psychoactive principle and is able to reduce and regulate the effects of THC, as it happens for the hemp varieties Caramagnola, Fibranova, and Ungherese (Grassi and Ranalli, 1999) and the authorised medical grade variety Bediol. Cannabis light (deriving from inflorescences of varieties allowed by the EU), then, for the chemovar characteristics, should contain little THC and much CBD.

As regards derivates from seeds circular No. 0015314 of 22/05/2009 of the Ministry of Labour, Health and Social Policies General Directorate of Food Safety and Nutrition - on Production and marketing of hemp seed products for use in human nutrition sectors declares that Considering that, according to current evidence, cannabinoids are produced only by the leaves and floral bracts, in turn of leaf origin, but not from seeds, the possibility of detecting traces of psychoactive substances in the products of seed processing (flours and oils) would be due exclusively to the accidental contamination of the floral organs, such as bracts, which can wrap the seed even when fully ripe. Hence, in-depth studies have been carried out to allow the use of plant seeds in the food sector and there was confirmation of the genetic absence of THC in cannabis seeds (with the consequent exclusion of the applicability of Presidential Decree 309/90) from the National Institute of Health and the Central Narcotics Office.

\section{Discussion}

The results of the farms survey are just to intend as an overview, as they considered only 30 case studies, and need of course a wider investigation in the future to totally describe the Italian hemp primary production, with a census conducted with public institutions cooperation, as there are not official data on the hemp cultivation surface in Italy but just an estimation by the farmers' association Coldiretti.

As specified in legislation 242/2016, hemp is as a crop capable of contributing to the reduction of the environmental impact in agriculture, to the reduction of the consumption of soils and desertification and loss of biodiversity, as well as a crop to be used as a possible substitute for surplus crops and as a rotation crop, ad this vision is reflected by the answers of the interviewees, that see 
hemp useful in delicate ecosystems such as mountain areas and an opportunity for young entrepreneurship. The fact that most of the farms buy the seeds from abroad also highlights the opportunity to create a market of certified seeds also in Italy, implying, however, the need to specifically register farms producing seeds in accordance with European legislation.

In the farmers' interviews, a direct connection between the choice of a variety and the final product was not found, also if selecting a genotype appropriate for an end-use application that is adaptable to an environment is of principal importance for successful hemp cultivation (Giupponi et al., 2020). This result sublines also the need of professional training for farmers and further studies to lead an appropriate choice of a variety targeted to a specific end-use. For what concerns other agricultural practices, as the plant distance, we saw instead a big difference linked to the enduse of the product, with a wider spacing ( 30 plants for square meter or even a plant every 3 square meter, with planting systems similar to $C$. sativa Indica ones) for flowers production and narrower for biomass and seeds production (till 150 plants for square meter). Many farms declared to do seeds scattering as planting practice, and also for what concerns this aspect there is need of farmers' training. Compared to other crops considered suitable for marginal agricultural land low-input systems, hemp presents a relatively short Minimum Length of Growing Season (90 days) and Growing Degree Days $\left(1400^{\circ} \mathrm{C}\right.$ ) (Von Cossel et al., 2019) so it was possible to find farms from the Alps to Southern Italy and Island. Again, as different varieties have different lengths of growing season (Pavlovic et al., 2019), it is of paramount importance the choice of a proper variety to the environment of cultivation. From the interviews it results that in many farms hemp is managed as a low input crop. In fact, as regards irrigation, only $30 \%$ farms need irrigation, while $60 \%$ do not; and only $7 \%$ of farms declared use of pesticides. Only one farm out of 30 uses chemical fertilisation together with organic manure. Almost all the farms interviewed, therefore, produce organically. C. sativa has been recently classified among the low-input multipurpose crop for biomass production in marginal agricultural lands (Von Cossel et al., 2019). Hemp is a rustic crop associated with environmental benefits - low pesticide and herbicide requirements and adaptability to a wide range of agronomic conditions - and has a range of current and potential uses as evidence of its value as an alternative cash crop for farmers (Randall and Bennet, 2004), as other minor crops (Giorgi et al., 2017; Giupponi et al., 2018, 2019). It is important to channel the stakeholders' attention and the renewed interest towards hemp through research and further studies on the economic and environmental sustainability of this crop are of paramount importance, to provide a complete and deep information to established farmers and new entries in agricultural activities. A deeper information on hemp cultivation economic impact, yield and different utilisations (in agreement with law) or other success indicator is needed to understand if this potentiality is just embedded in the stakeholders' opinion or it is a real possibility for Italian agriculture.

For what concerns the end product of the farms interviewed, the research results showed that some farms provide a product for transformation while others have a complete production chain as part of the farm or cooperate with local businesses for direct transformation. Only five farms declared selling inflorescences for technical use. In the discussion of the legal framework the possible end products of hemp listed in the legislation 142/2016 were described and, apart from one farm that indicates the not welldefined use as technical use as the only use of the hemp cultivation, all the crops of the farms in the survey are destined for purposes specified clearly by Italian legislation.
Other than that, more than $20 \%$ declared that they accompany their activity with cultural, multifunctional and educational activities, in particular courses and public events, educational laboratories (for production of food, food oil or cosmetics), environmental conservation and remediation, gastronomy showrooms. This is also in compliance with legislation 142/2016, that encourages the "support and promotion of the cultivation and supply chain of hemp (Cannabis sativa L.). This is also very interesting in a contest, like that of Italy, where agritourism is a very important aspect of agricultural activities.

None of the farms interviewed considers the construction sector, the pulp and paper and the automotive industry and only four declared to produce a small amount of fibres. However, the construction sector, the pulp and paper and the automotive industry are the most important markets for hemp fibres produced in the EU (Karus and Vogt, 2004). Almost a quarter of the hemp fibres used in industrial applications is to be found in composites (automotive and aerospace industry, sporting goods etc.), structural and building materials, geo-textiles and others (Zimniewska et WladykaPrzybylak, 2016).

For what concerns the fibre production in Italy, this is a very burning issue, because as it can be observed from historical documents (Peglione, 1919), Italy used to be famous for quality fibre production, but at the present time there is a lack of technology, as in the past the process depended mostly on the presence of a large quantity of labourers in the fields, and was long and performed totally by hand, a method nowadays totally impossible with the current labour costs. Although there would be a market in Europe for quality fibre for textiles, in 2001 the area under cultivation was insufficient to meet the demand for industrial hemp fibres. The balance was supplied by the processing of hemp stalks and pre-decorticated fibres from previous years (Karus and Vogt, 2004). Current research in Europe is focused on developing a less labour- and resource-intensive chemical retting process, but technological breakthroughs have yet to occur (Kessler and Kohler, 1996). The most important world producer of hemp is China and, as referred by Amaducci et al. (2015), till recent years the fibre production system is still just partially mechanised: for the harvest method of industrial hemp, in the Northern part of China, stems are cut at the bottom, dew retted in the fields, peeled by machine or manpower, or scutched with a machine; in the Southern part of China, stems are cut, top branches and leaves removed, graded by diameter, decorticated with a small machines (by decorticating fresh stem method) in the field or peeled manually on a ground nearby the house. Thus, mechanised farming and a cultivation managing system of less labour cost will be the main direction of the development for hemp production in the future. As in Europe, in Italy there is a technological gap to produce high-quality fibre for textiles and the only four examples observed of production of raw fibre in the farms surveyed were for educational or small-scale artisanal production.

This overview wants to highlight the need for more consistent cooperation with government and research to develop an Italian production chain and a less labour- and resource-intensive chemical retting process by means of a technological breakthrough, other than improving some farms mechanisation and spreading good practices even at a basic level. In Italy, a first experiment to produce specific machinery to process hemp bales was realised through collaboration between Piedmont Region, the CNR Imamoter Group Standardisation, Safety and Quality and Assocanapa. The objective of the research project was the construction of a prototype of standard machinery for processing hemp straws packed in round bales separating the fibre from the 
shives and obtaining technical fibre and shives with adequate fibre cleaning levels in order to be able to allocate the material to the production of good quality soundproofing and insulation panels. The implementation of the project, conceived by the two partners in 2006/2007, started at the end of 2008. Another important activity was promoted in the Trentino-Alto Adige Region, with the project called Free Field in 2016 for the transformation of hemp in the South Tyrol area and the production of furnishing and design elements with the material obtained with the use of a prototype, a small mobile machine that can process the stem and collect and clean the fibre already in the fields to obtain a raw material by which to make various types of textile products (shoes, carpets, curtains).

In our survey, seeds were an important product, for producing flour for baking as well as decorticated seeds to sell as superfood or hemp oil. The use of hemp seeds and their derivates is confirmed as an innovative superfood (Pavlovic et al., 2019). As a food ingredient, hempseed has been shown to be highly nutritious, containing $20 \%$ high-quality digestible proteins. About $65 \%$ of the total hemp protein consists of a single storage protein, edestin and it has been stated that, differently from soybean seeds which are abundant in trypsin inhibitors that require thermal treatment for inactivation, hemp seeds present very low amounts of these antinutritional factors and are therefore more digestible (Malomo et $a l ., 2015)$. Due to the high content in essential amino acids of edestin, hemp seed proteins can be used as a superfood. The seed is approximately $29-34 \%$ oil by weight, and the oil can be used for both human consumption and industrial applications. The oil contains roughly the same ratio of linoleic and linolenic acids found in a nutritionally balanced diet (Galasso et al., 2016), Particularly, the level of $\omega 6$ is thus an interesting resource for manufacturing dietary supplements (Mölleken and Theimer, 1997). Hempseed oil has been sold as a nutritional supplement in health food stores, as well as an ingredient for body-care products including lotions, moisturizers, shampoos, and lip balms (Marshall, 1998).

As shown by this research, in the Italian production chain hemp seeds and inflorescences are often destined for cosmetic use, while the same number of farms wish to use their inflorescences for herbal remedies and the extraction of active ingredients. There is growing interest in the valorisation of hemp inflorescences that could have potential pharmacological effects (Amaducci et al., 2015 ) and, indeed, hemp essential oil is reported to have an intriguing antimicrobial activity (Zengin et al., 2018), whereas the whole decocted plant is used at very low doses for migraine, as a pain reliever and to prevent cognitive decline. Hemp is also a prolific producer of bioactive secondary metabolites, and their recovery from inflorescences, for example for use as essential oil (Bertoli et al., 2010) contributes to defining this plant as a multipurpose crop. The most important secondary metabolites are phytocannabinoids that have received attention due to their biomedical relevance. Acidic forms of cannabinoids are exclusively biosynthesized in the trichromes: inflorescences of industrial hemp varieties are particularly rich in cannabidiolic acid (CBDA) that is susceptible to spontaneous decarboxylation to cannabidiol (CBD) under favourable environmental factors, such as heat and light. CBD is responsible for a variety of pharmacological actions that could have some remarkable applications, but unlike THC, CBD does not possess any psychoactive effects (Russo, 2011), which is the reason why CBD dietary supplements obtained from different industrial cannabis chemotypes have become particularly widespread (Pavlovic et al., 2018).

Further important feedbacks on the hemp production chain were in addition received by farmers: these highlighted the need for technicians to follow and improve the cultivation of hemp. Limited information is available regarding the effect of environment and management on plant quality characteristics (of fibre, seed and secondary metabolites). Evaluation of commercial varieties on the basis of their suitability for different end use applications is also lacking. (Amaducci, 2015). This leads to farmers' comments on the lack of expertise in the field. However, hemp is a niche crop that holds great potential in the context of a developing bio-based economy. In Italy, there are many virtuous cases of value chains, such as the first factory for the primary transformation of the straw of southern Italy hemp opened in Puglia region, which processes the hemp straws collected from the farmers of the area to transform it into the two constituent parts: the shives (woody inner part) and the technical fibre (short) that will be used for different industrial applications, such as mulching, animal litter, biobased construction materials etc. The business in 2017 worked with 253 farms with a total of 400 ha. The fully loaded processing plant is able to process 1.2 tonnes/hour of straw mechanically, giving 19.2 tonnes/day and 5760 tonnes/year at full speed (two shifts). Depending on the agricultural yields in biomass, an area of about 500/700 hectares is covered. Many artisanal and innovative uses of hemp are giving space to entrepreneurship as the first patent for producing Filament for FDM 3D printers to create objects in Hemp Bio Plastic from hemp industrial waste in Sicily or, always in Sicily, the creation of a transformation plant for cannabis extracts involving already a network of farmers for 300 ha of hemp fields and a Canadian entrepreneurship in partnership with the Department of Agriculture, Food and Environment of the University of Catania.

The legislation framework analysis showed how the legal aspects of the cultivation of hemp in Italy had a long and controversial history until recent years, due to the unique characteristics of this crop and then influencing its production. As regards the analysis of European and Italian legislation, the European Union is explicitly interested in promoting the cultivation of hemp. According to the above-mentioned European legislation, direct payments have been established for this crop and the responsibility of the state member for the strict control of the crops is specified. On this topic, the Italian law 242/2016 defines that: the implementation of the provisions of this law shall be carried out within the framework of the human, instrumental and financial resources available under current legislation and, in any case, without new or greater costs for public finance, but it is very likely that such a huge increase of control work by control bodies would require a significant amount of human and material resources. In Switzerland, for example, police forces have complained that it was impossible to distinguish the new light marijuana from the usual psychoactive cannabis that continues to be illegal. However, in Switzerland light cannabis has been classified as a tobacco substitute product and is sold in packages like those of shredded tobacco and taxed in the same way as cigarettes. The market is in such fast expansion that now not only cannabis inflorescences are available, but also pure CBD crystals and even hashish light, with $19 \%$ of CBD. Cannabis light, indeed, (deriving from the seeds allowed by the EU) therefore contains little THC and much CBD.

Furthermore, also according to the WHO (World Health Organisation) the situation is not yet clear: since June 2018 WHO and ECDD (Expert Committee on Drug Dependence) have started to elaborate an opinion on the medical use and the possible risks of cannabis (which at this time in the international drug control treaties is similar to any kind of drug, according to treaties dating back to the 1950s) and in particular on non-psychotropic substances (CBD) and plan to present an update to the drug 
Convention from March 2019. This would allow a greater possibility of medical access or anyway an unequivocal international opinion and research on both medical cannabis and the new substance considered, CBD.

In the US, the Drug Enforcement Agency (DEA) is adamantly opposed to industrial hemp cultivation in the United States because it is very difficult to distinguish between industrial hemp, which has low THC content, and marijuana (Vantreese, 1998). So, for Italy, this will be an additional public cost if, as in the United States, Switzerland and Canada, funds must be devoted to the legal control of crops. The difficulties in analytical platforms necessary for the controls and eventual product certification, meaning at least a microbiological profile (CBT, Molds-Aspergillus, pathogens), a pesticide profile (OCs OPs PCBs Dioxins IPA) a heavy metal profile and the analytical platform required, involving expensive scientific instruments (GC-MS, GC-MS / MS, LC HRMS Orbitrap, ICP-MS) for the cannabinoids content analyses should also be considered.

\section{Conclusions}

This study was conducted to provide an overview of the hemp production chain in Italy, from agricultural practices to crop use and the possible role of this field crop in sustainable development. The connection with social sciences regarding hemp legislation and commercial and industrial activities was also considered.

As it is clear from the critical analyses of European and Italian regulation, there is a need for a clear system of control by verification bodies, that would probably involve an increase in bureaucracy and of costs for labour and analytical platforms for the controls, in particular for what regards grow shops, a phenomenon significantly growing in the last decade. The USA, Canada and Switzerland had to devote funds to the legal control of crops (Randall and Bennet, 2004). Although hemp production could signify an increase in costs for the Italian government, this research also highlights that the farms comply with European and Italian legislation, there are examples of multifunctional farms, many are recent and are run by young entrepreneurs and allow the use of marginal abandoned territories such as mountain areas.

The growing attention to the cultivation of hemp from the scientific community and chain operators, especially consumers, has also led Italian farmers to take an interest in this crop. Its renewed appeal derives from the multiple possibilities of use of the plant and from growing demand from the consumer for eco-compatible and sustainable products. In fact, hemp can provide fabrics, food, paper, plastic, paint, fuel and building materials. The revaluation of this crop could therefore provide an excellent boost for an economic and environmental recovery, in a context (as in Italy) characterised by a strong environmental as well as economic crisis. The development of a multi-end use and low input crop such as hemp would also be coherent with the activities proposed for smart development in line with the United Nations 2030 Agenda. The low environmental impact of this cultivation is in agreement with European regulations about organic agriculture (Regulation 2018/848) and the recent 17 Sustainable Development Goals (SDG) established by the United Nations for the global agenda 2030 (United Nations, 2015).

It is also to be hoped that more resources can be provided to study, research and promote this important Italian crop.

\section{Highlights}

- In the last few years hemp production in Italy is increasing. - In Italy there has been an important development of economic activities connected with hemp.

- Regulation and agronomic practices on hemp cultivation in Italy need improvement.

\section{References}

Amaducci S, Scordia D, Liu FH, Zhang Q, Guo H, Testa G, Cosentino SL, 2015. Key cultivation techniques for hemp in Europe and China. Ind. Crop. Prod. 68:2-16.

Amar MB, 2006. Cannabinoids in medicine: A review of their therapeutic potential. J. Ethnopharmacol. 105:1-25.

Bertoli A, Tozzi S, Pistelli L, Angelini L, 2010. Fibre hemp inflorescences: From crop-residues to essential oil production. Ind. Crop. Prod. 32:329-37.

Bouloc P, 2013. The agricultural economics of hemp. In: Bouloc P (Ed.), Hemp Industrial Production and Uses. CABI, Wollingford, UK, pp. 128-144.

Bruck WF, 1911. Studien über den Hanfbau in Italien: mit 5 Fig. u. 1 Kurve. Mittler.

Calvi L, Pavlovic R, Panseri S, Giupponi L, Leoni V, Giorgi A, 2018. Quality traits of Medical Cannabis sativa L. inflorescences and derived products based on comprehensive analytical investigation. Recent Adv Cannabinoid Res IntechOpen DOI: 10.5772/intechopen.79539.

Carus M, Karst S, Kauffmann A, Hobson J, Bertucelli S, 2013. The European Hemp Industry: Cultivation, Processing and Applications for Fibres, Shives and Seeds. European hemp Industry Association, pp. 1-9.

Decorte T, 2010. Small Scale Domestic Cannabis Cultivation: An Anonymous Web Survey among 659 Cannabis Cultivators in Belgium. Contemp. Drug Probl. 37:341-70.

Elfordy S, Lucas F, Tancret F, Scudeller Y, Goudet L, 2008. Mechanical and thermal properties of lime and hemp concrete ('hempcrete') manufactured by a projection process. Cons. Build. Mater. 22:2116-23.

Faux AM, Draye X, Lambert R, d'Andrimont R, Raulier P, Bertin $P, 2013$. The relationship of stem and seed yields to flowering phenology and sex expression in monoecious hemp (Cannabis sativa L.). Eur. J. Agron. 47:11-22.

Galasso I, Russo R, Mapelli S, Ponzoni E, Brambilla IM, Battelli G, Reggiani R, 2016. Variability in Seed Traits in a Collection of Cannabis sativa L. Genotypes. Front. Plant Sci. 7:688.

Giorgi A, Pentimalli D, Giupponi L, Panseri S, 2017. Quality traits of saffron (Crocus sativus L.) produced in the Italian Alps. Open Agriculture 2:52-7.

Giupponi L, Ceciliani G, Leoni V, Panseri S, Pavlovic R, Lingua G, Di Filippo A, Giorgi A, 2019. Quality traits of saffron produced in Italy: geographical area effect and good practices. J. Appl. Botany Food Qual. 92:336-42.

Giupponi L, Leoni V, Pavlovic R, Giorgi A, 2020. Influence of altitude on phytochemical composition of hemp inflorescence: a metabolomic approach. Molecules 25:1381.

Giupponi L, Tamburini A, Giorgi A, 2018. Prospects for broader cultivation and commercialisation of copafam, a local variety of Phaseolus coccineus L., in the Brescia pre-Alps. Mount. Res. Develop. 38:24-34.

Grassi G, Ranalli P, 1999. Detecting and monitoring plant THC content: Innovative and conventional methods. In: P. Ranalli 
(Ed.), Advances in hemp research. The Haworth Press, Binghamton, New York, USA, pp. 61-84.

Hazekamp A, Fischedick JT, 2012. Cannabis - from cultivar to chemovar. Drug Test. Analysis 4:660-7.

Holbery J, Houston D, 2006. Natural-fibre-reinforced polymer composites in automotive applications. J. Miner. Met. Mater. Soc. 58:80-6.

Jarabo R, Fuente E, Monte MC, Savastano Jr H, Mutjé P, Negro C, 2012. Use of cellulose fibres from hemp core in fibre-cement production. Effect on flocculation, retention, drainage and product properties. Ind. Crops Prod. 39:89-96.

Karus M, Vogt D, 2004. European hemp industry: Cultivation, processing and product lines Euphytica 140:7-12.

Kessler RW, Kohler R, 1996. New strategies for exploiting flax and hemp. Chemtech December:34-42.

Malomo SA, Onuh JO, Girgih AT, Aluko RE, 2015. Structural and antihypertensive properties of 802 enzymatic hemp seed protein hydrolysates. Nutrients 7:7616-32.

Marshall T, 1998. Is there a market for hemp oil? Alberta Hemp Symposium Proceedings. Alberta Agriculture, Food and Rural Development, Edmonton, Alberta, USA.

McPartland JM, 2018. Cannabis systematics at the levels of family, genus, and species. Cannabis Cannabinoid Res. 3.1, DOI: 10.1089/can.2018.0039.

Mölleken H, Theimer RR, 1997. Survey of minor fatty acids in Cannabis sativa L. fruits of various origins. J. Int. Hemp Assoc. 4:13-7.

Musio S, Müssig J, Amaducci S, 2018. Optimising hemp fiber production for high performance composite applications. Front Plant Sci. 9:1702.

Pavlovic R, Nenna G, Calvi L, Panseri S, Borgonovo G, Giupponi L, Cannazza G, Giorgi A, 2018. Quality traits of 820 "cannabidiol oils": cannabinoids content, terpene fingerprint and oxidation stability of European commercially available preparations. Molecules 23:1920.

Pavlovic R, Panseri S, Giupponi L, Leoni V, Citti C, Cattaneo C, Cavaletto M, Giorgi A, 2019. Phytochemical and ecological analysis of two varieties of hemp (Cannabis sativa L.) grown in a mountain environment of Italian Alps. Front. Plant Sci. [In press].

Peglione V, 1991. Le nostre piante industriali. Canapa, lino, tabac- co, bietola etc. Zanichelli, Bologna, Italy, pp. 161.

Randall TR, Fortenbery and Bennet M, 2004. Opportunities for commercial hemp production. Review of agricultural economics. Appl. Econ. Perspect. Policy. 26:97-117.

Russo EB, 2011. Taming THC: Potential cannabis synergy and phytocannabinoid-terpenoid entourage effects. Br. J. Pharmacol. 163:1344-64.

Rustichelli C, Ferioli V, Baraldi M, Zanoli P, Gamberini G, 1998. Analysis of cannabinoids in fibre hemp plant varieties (Cannabis sativa L.) by high $\square$ performance liquid chromatography. Chromatographia 48:215.

Tang K, Struik PC, Yin X, Thouminot C, Bjelková M, Stramkale V, 2016. Comparing hemp (Cannabis sativa L.) cultivars for dual-purpose production under contrasting environments. Ind. Crop Prod. 87:433-447.

United Nations, 2015. Transforming our world: the 2030 Agenda for Sustainable Development. Available from: https://undocs.org/A/RES/70/1 Accessed: 11th April 2019.

Vantreese VL, 1998. Industrial hemp: global operations, local implications. Dept. Agr. Econ., University of Kentucky, 1998. Available from: http://www.industrialhemp.net/pdf/abs hemploc.pdf

Von Cossel M, Lewandowski I, Elbersen B, Staritsky I, Van Eupen M, Iqbal Y, Mantel S, Scordia D, Testa G, Cosentino SL, Maliarenko O, Eleftheriadis I, Zanetti F, Monti A, Lazdina D, Neimane S, Lamy I, Ciadamidaro L, Sanz M, Carrasco JE, Ciria P, McCallum I, Trindade LM, Van Loo EN, Elbersen W, Fernando AL, Papazoglou EG, Alexopoulou E, 2019. Marginal agricultural land low-input systems for biomass production. Energies. 12:3123.

Zimniewska M, Wladyka-Przybylak M, 2016. Textile science and clothing technology. In: S. Rana and R. Fangueiro (Eds.), Fibrous and textile materials for composite applications. Springer Science \& Business Media, Singapore.

Zengin G, Menghini L, Di Sotto A, Mancinelli R, Sisto F, Carradori S, Cesa S, Fraschetti C, Filippi A, Angiolella L, Locatelli M, Mannina L, Ingallina C, Puca V, D’Antonio M, Grande R, 2018. Chromatographic analyses, in vitro biological activities, and cytotoxicity of Cannabis sativa L. essential oil: a multidisciplinary study. Molecules 23: pii: E3266. 